\section{Hidden subsidies and risks pump up real price of oil}

SIR - Congratulations on your excellent Biofuels Special (Nature 444, 654 and 669-678; 2006). Not only is this an important topic for scientists and environmentalists, but also developing energy products that move the United States away from its over-dependence on oil is a critical national-security priority.

There are many exciting possibilities for expanding renewable fuels in the United States and around the world. Today's ethanol from corn and sugar will be complemented by cellulosic ethanol from many energy crops, as well as by next-generation biodiesel and perhaps other renewable fuels that have yet to be developed. Moreover, these will complement liquid fuels made from abundant coal reserves.

Although I agree that markets need to determine which fuels emerge as the most competitive, we should recognize that these new fuels are not competing on a level playing field with oil. The true costs of oil to our economy and national security are much higher than the price paid at the pump. Much of the world's oil is controlled by authoritarian regimes that increasingly use their oil resources for political gain. In addition, the price we pay for oil does not cover the risks to the economy from delivery disruptions, price spikes, environmental hazards and the vast cost of protecting supply routes and infrastructure. Milton R. Copulos, president of the National Defense Council Foundation, testified to the Senate Foreign Relations Committee last year that the minimum military subsidy Americans pay to protect Middle East oil trade routes is $\$ 50$ billion a year (see www.senate.gov/ $\sim$ foreign/hearings/2006/hrg060330a.html).

Consequently, Congress is debating a variable price floor for alternative fuels so that oil producers cannot use temporary price cuts to undercut the new fuels that make America more secure. Such a floor should allow all fuels to compete, so the best ones may emerge.

Dick Lugar

United States Senate, 306 Hart Senate Office Building, Washington DC 20510, USA

\section{Poaching laws are useless without solid enforcement}

SIR - Your News Snapshot of tigers in India's Nagarhole National Park ("A night out in the park" Nature 444, 413; 2006) quotes a conservationist's view that tiger conservation is more at risk from loss of habitat than from the tiger trade.

This may be true in a few protected areas such as Nagarhole, where anti-poaching laws protecting tigers and their prey are strictly enforced. However, only $23 \%$ of the priority landscapes where tigers survive today are protected areas (E. Dinerstein et al. Setting Priorities for the Conservation and Recovery of Wild Tigers: 2005-2015: A User's Guide WWF, WCS, Smithsonian and NFWF-STF, 2006), and enforcement in many of those places is poor. In 2005, for example, poachers were found to have wiped out the entire tiger population of Sariska Tiger Reserve in India (D. Banks and B. Wright Skinning the Cat: Crime and Politics of the Big Cat Skin Trade Environmental Investigation Agency/ Wildlife Protection Society of India, 2006).

If we want to save wild tigers, we will have to reduce demand for tiger parts and crack down on illegal trafficking throughout Asia. We also have to improve on-the-ground efforts beyond reserve boundaries to achieve real landscape-level conservation outcomes.

Brian Gratwicke

Save The Tiger Fund

1120 Connecticut Avenue NW, Suite 900, Washington DC 20036, USA

\section{Turks fighting back against anti-evolution forces}

SIR - Your recent Special Report "Antievolutionists raise their profile in Europe" (Nature 444, 406-407; 2006) draws attention to the strong anti-evolution climate in Turkey, and concludes pessimistically. However, the teaching of evolution is not a lost cause in Turkey.

It is true that the situation is grave. In a recent survey of acceptance of evolution, Turkey scored the worst among 25 countries, with less than $30 \%$ of the population accepting it (J. D. Miller et al. Science 313, 765-766; 2006).

The major reason for this has been the conservative influence on education in Turkey during the past 25 years. In 1985, the then minister of education contacted creationists in the United States, a cooperation that led to the inclusion of creationism in the high-school biology curriculum and textbooks.

Furthermore, anti-evolution views are not restricted to textbooks. In a study conducted by one of us in the capital, Ankara, last year, only $47 \%$ of the 147 biology and science teachers surveyed said they accepted evolution. More disturbing is that it was accepted by significantly fewer of the young teachers and by only $26 \%$ of the 257 14-year-old students.

On the other hand, Turkish scientists have been striving to reverse this trend. It has been publicly criticized by the Turkish Academy of Sciences (www.natcenscied.org/resources/ rncse_content/vol19/8371_cloning_ creationism_in_turkey_12_30_1899.asp). A group of graduate students known as Evrim Caliskanlari, or 'hard-workers for evolution', has started translating the University of California, Berkeley's Understanding Evolution website into Turkish (see www. universitekonseyleri.org/evrimcaliskanlari).

Most forcefully, a non-governmental association, Universite Konseyleri Dernegi, has filed a lawsuit against the Ministry of Education, demanding that creationism should be removed from textbooks and evolutionary biology should be covered appropriately in the curriculum.

The ministry has responded by asserting that darwinism is scientifically suspect using publications by the US intelligentdesign Discovery Institute for reference. It goes on to claim that developed countries are including creation-like theories in their curricula and to imply that evolution is not compatible with Turkish 'culture and values'. At this point it is unclear how the case will turn out.

If more Turkish scientists showed their support for the efforts that are being made, and put pressure on their academic bodies to take a pro-evolutionary position, this would certainly influence both the ministry and public opinion. Better late than never.

Mehmet Somel ${ }^{\star}$, Rahsan Nazli Ozturkler Somel $\dagger$, Aykut Kence $\%$

*Max Planck Institute for Evolutionary Anthropology, Deutscher Platz 6,

D-04103 Leipzig, Germany

†Department of Education Science,

Helmut Schmidt University, Holstenhofweg 85,

22043 Hamburg, Germany

†Department of Biology,

Middle East Technical University,

06531 Ankara, Turkey

\section{Readers see red over low-impact graphics}

SIR - Nature authors are increasingly using colour within figures. May I remind them and the graphics editors that a significant proportion of their readers, including me, cannot distinguish red from green? Issue number 7120 , for example, was not atypical in having six figures that used these two colours. The impact of their figures - and just possibly the impact factor of the journal - will be improved if all the audience can see all the data.

Chris Miall

School of Psychology, University of Birmingham, Birmingham B15 2TT, UK

Contributions to Correspondence may be submitted to corres@nature.com. They should be no longer than 500 words, and ideally shorter. 